\title{
Zinc oxide nanoparticles: a 90-day repeated-dose dermal toxicity study in rats
}

\author{
This article was published in the following Dove Press journal: \\ International Journal of Nanomedicine \\ 15 December 2014 \\ Number of times this article has been viewed
}

\author{
Hwa Jung Ryu',* \\ Mu Yeb Seo $2, *$ \\ Sung Kyu Jung' \\ Eun Ho Maeng ${ }^{2}$ \\ Seung-Young Lee ${ }^{2}$ \\ Dong-Hyouk Jang ${ }^{2}$ \\ Taek-Jin Lee ${ }^{2}$ \\ $\mathrm{Ki}$-Yeon Jo \\ Yu-Ri Kim ${ }^{3}$ \\ Kyu-Bong $\mathrm{Cho}^{4}$ \\ Meyoung-Kon $\mathrm{Kim}^{3}$ \\ Beom Jun Lee ${ }^{5}$ \\ Sang Wook Son'
}

'Department of Dermatology, Korea University College of Medicine, Seoul, ${ }^{2}$ Korea Testing and Research Institute, Gyunggido, ${ }^{3}$ Department of Biochemistry and Molecular Biology, Korea University College of Medicine, Seoul, ${ }^{4}$ Department of Clinical Laboratory Science, Shinheung College, Uijeongbu, ${ }^{5}$ College of Veterinary Medicine, Chungbuk National University, Cheongju, Republic of Korea

*These authors contributed equally to this work and both should be considered first authors

Correspondence: Beom Jun Lee College of Veterinary Medicine, Chungbuk National University, Naesudong-ro 52 , Heungdeok-gu, Cheongju-si, Chungbuk, Republic of Korea

Tel +82 $4326 \mid 3357$

Fax +82428218903

Email beomjun@cbu.ac.kr

Sang Wook Son

Department of Dermatology, Korea

University College of Medicine, 5-ka,

Anam-dong, Sungbuk-ku, Seoul, I 36-705,

Republic of Korea

$\mathrm{Tel}+8229206433$

Fax +8229230480

Email skin4u@korea.ac.kr
Abstract: Zinc oxide ( $\mathrm{ZnO})$ works as a long-lasting, broad-spectrum physical sunblock, and can prevent skin cancer, sunburn, and photoaging. Nanosized $\mathrm{ZnO}$ particles are used often in sunscreens due to consumer preference over larger sizes, which appear opaque when dermally applied. Although the US Food and Drug Administration approved the use of nanoparticles (NPs) in sunscreens in 1999, there are ongoing safety concerns. The aim of this study was to evaluate the subchronic toxicity of ZnO NPs after dermal application according to the Organization for Economic Cooperation and Development Test Guidelines 411 using Good Laboratory Practice. Sprague Dawley rats were randomly divided into eight (one control, one vehicle control, three experimental, and three recovery) groups. Different concentrations of ZnO NPs were dermally applied to the rats in the experimental groups for 90 days. Clinical observations as well as weight and food consumption were measured and recorded daily. Hematology and biochemistry parameters were determined. Gross pathologic and histopathologic examinations were performed on selected tissues from all animals. Analyses of tissue were undertaken to determine target organ tissue distribution. There was no increased mortality in the experimental group. Although there was dose-dependent irritation at the site of application, there were no abnormal findings related to $\mathrm{ZnO}$ NPs in other organs. Increased concentrations of $\mathrm{ZnO}$ in the liver, small intestine, large intestine, and feces were thought to result from oral ingestion of $\mathrm{ZnO}$ NPs via licking. Penetration of $\mathrm{ZnO}$ NPs through the skin seemed to be limited via the dermal route. This study demonstrates that there was no observed adverse effect of ZnO NPs up to $1,000 \mathrm{mg} / \mathrm{kg}$ body weight when they are applied dermally.

Keywords: zinc oxide, nanoparticles, subchronic toxicity, dermal exposure

\section{Introduction}

Many sunscreens contain zinc oxide $(\mathrm{ZnO})$ and titanium dioxide, since they not only physically reflect but also absorb ultraviolet light. When they are present as larger particles, they appear opaque and have a tendency to leave a film, which consumers dislike. Using ZnO nanoparticles (NPs), the opacity of sunscreen is decreased, resulting in increased compliance with use of sunblock. However, a significant concern with the use of nanotechnology-based products is that nanoscale materials may penetrate protective physical barriers, such as the skin, lungs, intestinal tract, and blood-brain barrier, and once internalized, may be harmful. The skin is the outermost barrier of the body and a route of entry for many foreign materials, including NPs. Recent studies have demonstrated that small amounts of zinc from $\mathrm{ZnO}$ particles in sunscreens applied outdoors are absorbed through human skin. ${ }^{1}$ In spite of these concerns, few studies have investigated the effects of ZnO NPs on the internal organs when they were applied to the skin repeatedly.

It is recognized that NPs have physicochemical characteristics that are very different from those of larger particles given that their surface area is proportionally greater, and 
so may be more toxic. There are worries that these NPs may escape immune surveillance and natural defense mechanisms because of their very small size. NPs could also form free radicals when internalized. $\mathrm{ZnO}$ NPs have been reported to elicit various adverse cellular effects, including genotoxicity ${ }^{2}$ and cytotoxicity. ${ }^{3}$ It has also been suggested that ultraviolet B irradiation causes increased dissociation of $\mathrm{Zn}^{2+}$ from $\mathrm{ZnO}$ and that the consequent accumulation of free or labile $\mathrm{Zn}^{2+}$ from sunscreen results in cytotoxicity and oxidative stress. ${ }^{3}$ However, the mechanisms underlying these adverse effects are not fully characterized. Decreased collagen content in the skin due to oxidative stress at the site of application of $\mathrm{ZnO}$ has been reported. ${ }^{4}$ It is important to know the toxic effects of $\mathrm{ZnO}$ when used chronically, in light of a report by Kertesz et $\mathrm{al}^{5}$ showing that penetration of nanomaterials into the skin after dermal exposure is time-dependent. We are likely to come into contact with $\mathrm{ZnO}$ NPs in everyday life, as they are contained in many cosmetic products. The 90-day repeated-dose toxicity test is often used to evaluate the subchronic toxicity of certain materials. In the present study, the subchronic toxicity of ZnO NPs $(20 \mathrm{~nm}$, negatively charged $\mathrm{ZnO}^{\mathrm{SM} 20(-)}$ ) was investigated in Sprague Dawley rats. The potential toxicity and safety of ZnO NPs was studied during 90 days of repeated dermal application with a 14-day recovery period according to Organization for Economic Co-operation and Development recommendations with Good Laboratory Practice. The objective was to identify potential target organ(s) for toxicity induced by ZnO NPs in rats to identify the no observed adverse effect level (NOAEL) value.

\section{Materials and methods Chemicals and animals}

$\mathrm{ZnO}$ NPs (20 nm, lot number 141319) were purchased from Sumitomo Osaka Cement Co Ltd (Osaka, Japan). The surface charge was modified with coating reagents, citrate for (-) charge $\left(\mathrm{ZnO}^{\mathrm{SM} 20(-)}\right)$, as reported previously. ${ }^{6}$ On scanning electron microscopy, $\mathrm{ZnO}^{\mathrm{SM} 20(-)}$ were determined to be an average of $29 \pm 3 \mathrm{~nm}$ and to be spherical in shape. The zeta potential of $\mathrm{ZnO}^{\mathrm{SM} 20(-)}$ was $-44.4 \pm 1.0 \mathrm{mV}$, with a negative surface charge. One hundred and thirty Sprague Dawley rats aged 6 weeks and weighing 150-210 g were obtained from an inhouse animal facility and housed in an animal room maintained at $21.8^{\circ} \mathrm{C} \pm 1^{\circ} \mathrm{C}$ and $50.8 \% \pm 10 \%$ relative humidity with an alternating 12:12-hour light-dark cycle. The rats were kept in stainless steel cages, and rodent food (Cargill Agri Purina Inc., Kyunggido, Republic of Korea) and reverse osmosis water were provided ad libitum. All animal procedures were reviewed and approved by the animal ethics committee. The rats were randomly divided into five groups. Different doses of $\mathrm{ZnO}^{\mathrm{SM} 20(-)}$ were dermally administered to rats in the experimental groups for 90 days. The groups and doses applied are listed in Table 1. Group 1 (normal control) animals were treated with distilled water for 90 days. Group 2 was treated dermally with HEPES (4-(2-hydroxyethyl)-1-piperazineethanesulfonic acid)-citrate buffer as a vehicle control group. Groups 3, 4, and 5 were treated dermally with $\mathrm{ZnO}^{\mathrm{SM} 20(-)}$ at doses of 250,500 , and $1,000 \mathrm{mg} / \mathrm{kg}$, respectively. In an unpublished study of 14-day repeated-dose toxicity in rats, significant toxicity was observed at doses of $2,000 \mathrm{mg} / \mathrm{kg}$, so a maximum dose of $1,000 \mathrm{mg} / \mathrm{kg}$ was used in this study, with $500 \mathrm{mg} / \mathrm{kg}$ as an intermediate dose and $250 \mathrm{mg} / \mathrm{kg}$ as a low dose (Table 1). There were also animals in recovery groups (Table 1). They were monitored for additional 14 days after the 90 day toxicity testing was done. They were rats from control, vehicle control, and $\mathrm{ZnO} 1000 \mathrm{mg} / \mathrm{kg}$ groups.

\section{Subchronic toxicity}

A 90-day repeated-dose dermal toxicity test was conducted as per Organization for Economic Co-operation and Development Test Guideline 411 with modifications for dosage, biochemical parameters, and histopathologic evaluation. The prepared $\mathrm{ZnO}$ NPs were applied to the skin to evaluate the toxicity of $\mathrm{ZnO}$ on repeated dermal exposure. A $5 \mathrm{~cm} \times 6 \mathrm{~cm}$ area on the back of each rat was clipped free of hair once a week. ZnO NPs were applied to approximately $10 \%$ of the total body surface area (about $4 \mathrm{~cm} \times 5 \mathrm{~cm}$ ). Sterile gauze was soaked in the $\mathrm{ZnO}^{\mathrm{SM} 20(-)}$ solution and attached to the hairless portion of the back and fixed with nonirritant tape, ie, Tegaderm ${ }^{\mathrm{TM}}$ (3M, St Paul, MN, USA) and Coban ${ }^{\mathrm{TM}}$ (3M), for 6 hours to prevent disruption of the $\mathrm{ZnO}$ patch.

Table I Treatment groups and dose levels of nanosized zinc oxide

\begin{tabular}{llll}
\hline Group & Dose & Animals (n) & Animals in recovery (n) \\
\hline GI & Control (distilled water) & 10 males, 10 females & 5 males, 5 females \\
G2 & Vehicle control (HEPES-citrate buffer) & 10 males, 10 females & 5 males, 5 females \\
G3 & $Z_{\text {nO }}^{S M 20(-)}, 250 \mathrm{mg} / \mathrm{kg}$ & 10 males, 10 females & \\
G4 & $Z_{\text {nO }}^{S M 20(-)}, 500 \mathrm{mg} / \mathrm{kg}$ & 10 males, 10 females & 5 males, 5 females \\
G5 & $Z^{S n O}$ & 10 males, 10 females & \\
\hline
\end{tabular}

Note: $\mathrm{ZnO}^{\text {sM20(-) }}$ purchased from Sumitomo Osaka Cement Co Ltd, Osaka, Japan.

Abbreviation: $\mathrm{ZnO}^{\mathrm{SM} 20(-)}$, zinc oxide nanoparticles $20 \mathrm{~nm}$ in size. 
After 6 hours of application, the site was cleaned with sterile water. This procedure was repeated every day for 90 days.

\section{Clinical observations}

Body weight and food and water intake were measured weekly. All 130 rats were observed daily for signs of abnormality and toxicity during the 90 days of treatment, and during the 14-day recovery period for the 30 rats in the recovery group.

\section{Ophthalmologic examination} and urinalysis

Ophthalmic appearance was observed with the naked eye before treatment and during the last week of the experiment. An ophthalmoscope (Genesis, Kowa Ltd, Nagoya, Japan) was used to observe the fundus oculi in the control group and in the G5 group after using a mydriatic agent (OcuTropine ${ }^{\circledR}$; Samil Pharmaceutical Co Ltd, Seoul, Republic of Korea) at the end of the experiment. Urine tests were performed during the last week of the study using Multistix ${ }^{\circledR} 10 \mathrm{SG}$ strips (Siemens AG, Erlangen, Germany) and a urine analyzer (Clinitek 500, Bayer Inc., Pittsburgh, PA, USA) to determine specific gravity, $\mathrm{pH}$, leukocyte count, nitrite, protein, glucose, ketones, urobilinogen, bilirubin, and blood in urine. Urinary sediments were analyzed from a fresh 3-hour collection of urine, and the amount of urine was measured from the 24-hour collected urine from rats of the control and G5 group.

\section{Hematology and biochemistry}

Blood samples were taken from an abdominal artery after each animal was deeply anesthetized with isoflurane. The animals were fasted for 18 hours before blood sampling. Hematologic analyses were performed using an automatic hematologic analyzer (Advia ${ }^{\circledR}$ 120E; Siemens AG). Parameters measured in the blood samples were: white blood cell count, differential counts (neutrophils, lymphocytes, monocytes, eosinophils, basophils), red blood cell count, hemoglobin, hematocrit, mean cell volume, mean corpuscular hemoglobin, mean cell hemoglobin, mean cell hemoglobin concentration, and platelet count. The reticulocyte ratio was assessed for all animals using staining and microscopy techniques. Prothrombin time and activated partial thromboplastin time were performed using blood samples collected into a $9 \mathrm{NC}$ BD Vacutainer ${ }^{\circledR}$ (BD Biosciences, San Jose, CA, USA) containing $3.2 \%$ sodium citrate as an anticoagulant with centrifugation at 3,000 rpm for 10 minutes.

Biochemical analyses of serum samples were performed using an automatic chemistry analyzer (Hitachi 7060; Hitachi
Ltd, Tokyo, Japan, and EasyLyte; Werfen Medical, Newtonville, IL, USA). Biochemical parameters measured were total protein, albumin, albumin/globulin ratio, total bilirubin, alkaline phosphatase, alanine aminotransferase, aspartate aminotransferase, creatinine, blood urea nitrogen, total cholesterol, triglycerides, blood glucose, calcium, inorganic phosphorus, creatine kinase, sodium, potassium, and chlorine.

\section{Necropsy findings, organ weight measurement, and pathologic examination}

After collection of blood samples, the animals were sacrificed under deep anesthesia with isoflurane. After exsanguination, the external surface, all orifices, the cranial cavity, and the thoracic and abdominal cavities and their contents were visually observed for any signs of gross abnormality. Absolute and relative organ weights (organ weight/body weight) were measured for each rat. For paired organs, the sum of those organs was used.

After collection, the organs were preserved in $10 \%$ phosphate-buffered formalin solution, with the testes preserved in Davidson's solution in preparation for histopathologic examination. Organs collected included the skin, lymph nodes, salivary glands (submandibular), bone, bone marrow (sternum, femur), thymus, trachea, bronchus, lungs, heart, thyroid gland, parathyroid glands, tongue, esophagus, stomach, small intestine, large intestine, liver, spleen, pancreas, kidneys, adrenal glands, bladder, seminal vesicles, prostate gland, testes, epididymis, ovaries, uterus, vagina, brain, pituitary gland, spinal cord, eyes, sciatic nerve, and skeletal muscle.

\section{Tissue distribution}

A $1 \mathrm{~mL}$ blood sample was drawn from the caudal vein, and feces were collected before necropsy. Next, the brain, liver, kidneys, testes (or ovaries), spleen, lung, stomach, small intestine, large intestine, and skin were collected and measured after removing the fat and washing with normal saline. The collected organs were preprocessed before weighing and temporarily stored in an ice box with dry ice. They were then analyzed using inductively coupled plasma atomic emission spectroscopy (Ultima 2; Horiba Jobin Yvon Inc., Tokyo, Japan) and an ME254 analytical balance (Sartorius AG, Göttingen, Germany).

\section{Statistical analysis}

The data obtained for body weight, food and water consumption, hematology and biochemistry, and organ weight were evaluated by one-way analysis of variance after Levene's 
test to examine the homogeneity of their variance. If the data were determined to be homogeneous, the data were analyzed using Scheffe's multiple comparison test, and if not homogeneous, by Dunnett's T3 multiple comparison test. The data were analyzed using Statistical Package for the Social Sciences software version 12.0 (SPSS Inc, Chicago, IL, USA), and differences were considered to be statistically significant at $P$-values less than 0.05 .

\section{Results}

\section{Clinical observations}

The main sign associated with application of $\mathrm{ZnO}$ NPs was formation of skin crusts. At first, this appeared in the $\mathrm{G} 5(1,000 \mathrm{mg} / \mathrm{kg})$ group 2 days after initiation of $\mathrm{ZnO}^{\mathrm{SM} 20(-)}$, and all groups showed crust formation in a dose-dependent manner. Skin crusts also appeared in the vehicle control group, but resolved after 7 days. Skin crusts from male rats in the $1,000 \mathrm{mg} / \mathrm{kg}$ group were biopsied, and found to contain areas of hyperkeratosis and papillomatosis when compared with the normal skin of controls (Figure 1). Scar tissue developed at the application site in one female rat in the G5 group. No difference in body weight was observed between the experimental and control groups. Food intake in male rats from the $500 \mathrm{mg} / \mathrm{kg}$ and $1,000 \mathrm{mg} / \mathrm{kg}$ groups was significantly decreased in comparison with that in the control group at week 2 . Food intake was decreased in female rats from the $250 \mathrm{mg} / \mathrm{kg}$ group at week 1 and increased in the $1,000 \mathrm{mg} / \mathrm{kg}$ group at week 2 in comparison with the control group. During the recovery period, food intake was decreased in male rats in the $1,000 \mathrm{mg} / \mathrm{kg}$ group after week 2 of recovery. Male rats in the $1,000 \mathrm{mg} / \mathrm{kg}$ group consumed less water than the control group at week 11. In recovery, water consumption increased significantly in female rats from the $1,000 \mathrm{mg} / \mathrm{kg}$ group at weeks 1 and 2. All of these changes were considered to be temporary, given that body weight did not change significantly. Further, these changes were not dose-dependent, so were not considered to be toxic effects of $\mathrm{ZnO}$ NPs.

\section{Ophthalmologic examination and urinalysis}

No significant changes were observed on ophthalmologic examination or urinalysis.

\section{Hematology and biochemistry}

A decreased number of lymphocytes was documented in male rats from the $1,000 \mathrm{mg} / \mathrm{kg}$ group in comparison with the control group $(P<0.05)$. Increased mean corpuscular hemoglobin was observed in female rats from the $1,000 \mathrm{mg} / \mathrm{kg}$ group in comparison with the vehicle control group ( $P<0.05$, see Table 2$)$.

During the recovery period, aspartate aminotransferase and creatine kinase levels were decreased in male rats from the $1,000 \mathrm{mg} / \mathrm{kg}$ group $(P<0.01)$ in comparison with the vehicle control group. An increased albumin/globulin ratio was seen during the recovery period in female rats from the $1,000 \mathrm{mg} / \mathrm{kg}$ group in comparison with the control group $(P<0.05)$. However, these statistically significant changes were not considered to be related to the toxic effects of $\mathrm{ZnO}$, since there was no dose-dependent relationship and the results were not consistent between male and female rats (see Table 3 ).

\section{Necropsy findings, organ weight, and pathologic examination}

Right prostate gland hyperplasia and a yellowish mass in the head of the right epididymis was observed in one male rat each, and both were from the vehicle control

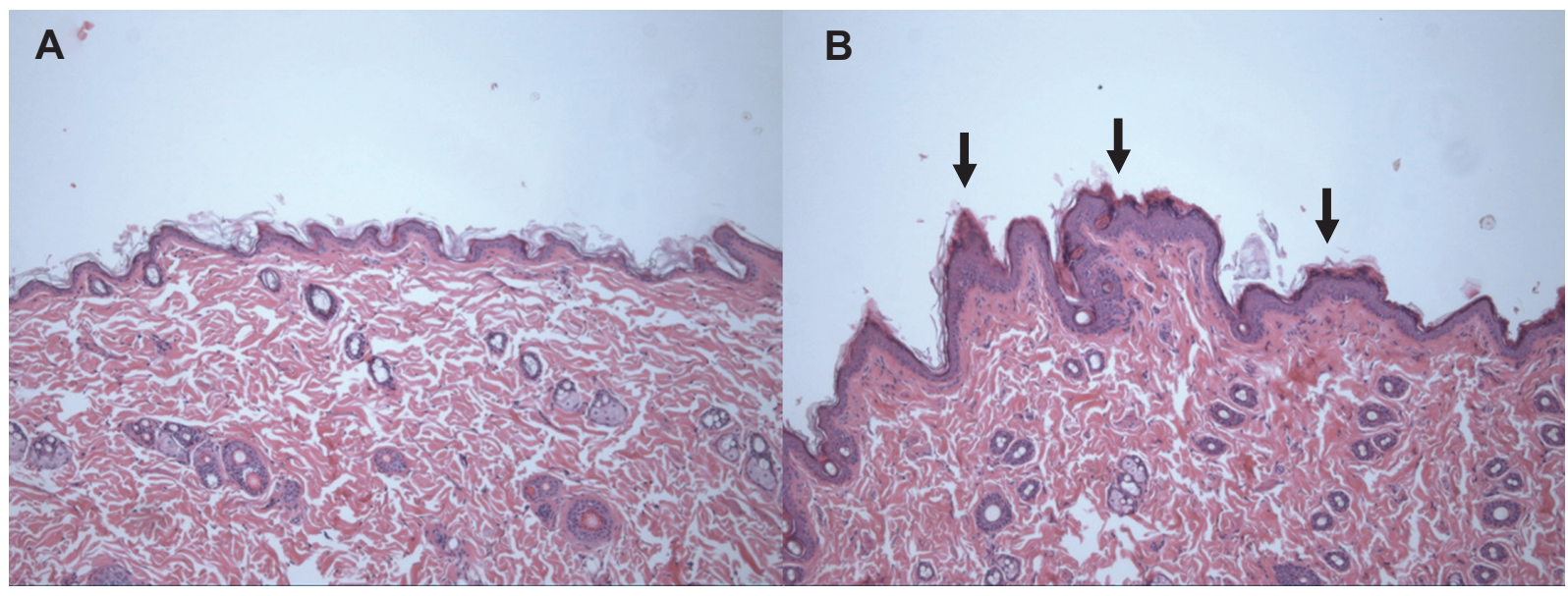

Figure I Histopathologic changes in the skin after treatment with zinc oxide nanoparticles at a dose of I,000 mg/kg for 90 days. Skin sections were stained with hematoxylin and eosin (100X). (A) Control group and (B) I,000 mg/kg treatment group.

Note: Arrows in (B) represent hyperkeratosis. 


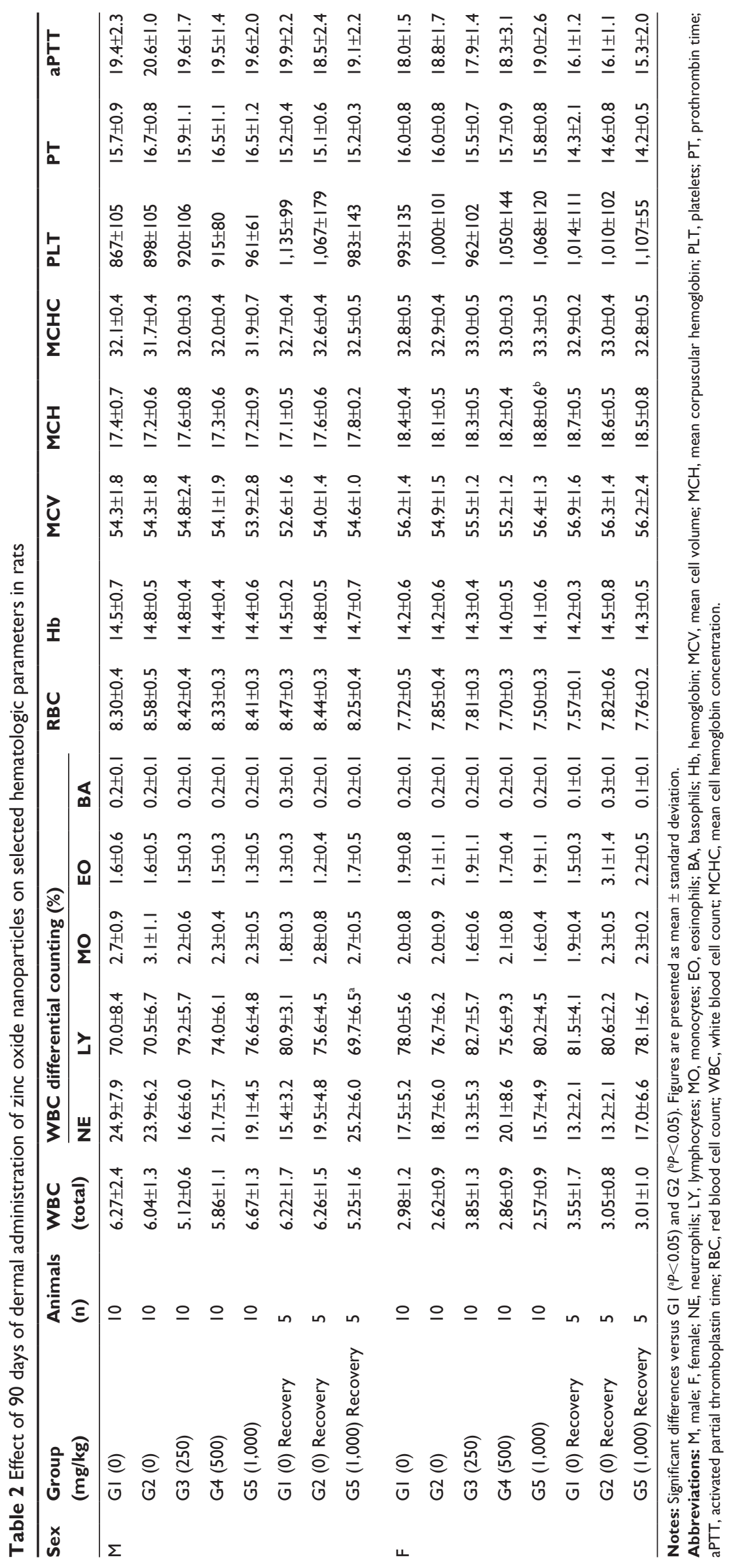


Table 3 Effect of 90 days of dermal administration of zinc oxide nanoparticles on selected biochemical parameters in male and female rats

\begin{tabular}{|c|c|c|c|c|c|c|c|c|c|}
\hline Sex & Group (mg/kg) & Animals (n) & $\begin{array}{l}\text { TP } \\
\text { (g/L) }\end{array}$ & $\begin{array}{l}\text { A/G } \\
\text { (g/L) }\end{array}$ & $\begin{array}{l}\text { AST } \\
\text { (U/L) }\end{array}$ & $\begin{array}{l}\text { ALT } \\
\text { (U/L) }\end{array}$ & $\begin{array}{l}\text { CK } \\
\text { (IU/L) }\end{array}$ & $\begin{array}{l}\text { BUN } \\
\text { (mg/L) }\end{array}$ & $\begin{array}{l}\text { Crea } \\
(\mathrm{mg} / \mathrm{L})\end{array}$ \\
\hline \multirow[t]{8}{*}{ Male } & GI (0) & 10 & $5.9 \pm 0.3$ & $0.7 \pm 0.1$ & $155 \pm 33$ & $42 \pm 7$ & $473 \pm 248$ & $14.4 \pm 2.4$ & $0.6 \pm 0.0$ \\
\hline & G2 $(0)$ & 10 & $5.8 \pm 0.2$ & $0.8 \pm 0.1$ & $153 \pm 28$ & $40 \pm 8$ & $470 \pm 245$ & $14.0 \pm 1.0$ & $0.5 \pm 0.0$ \\
\hline & G3 (250) & 10 & $5.8 \pm 0.4$ & $0.7 \pm 0.1$ & $153 \pm 29$ & $42 \pm 13$ & $643 \pm 369$ & $15.2 \pm 1.6$ & $0.5 \pm 0.1$ \\
\hline & G4 (500) & 10 & $5.7 \pm 0.2$ & $0.8 \pm 0.1$ & $158 \pm 62$ & $50 \pm 36$ & $538 \pm 245$ & $13.9 \pm 1.4$ & $0.5 \pm 0.0$ \\
\hline & G5 $(1,000)$ & 10 & $5.7 \pm 0.3$ & $0.7 \pm 0.1$ & $174 \pm 53$ & $46 \pm 23$ & $647 \pm 291$ & $15.8 \pm 1.2$ & $0.5 \pm 0.1$ \\
\hline & GI (0) Recovery & 5 & $6.9 \pm 0.5$ & $0.7 \pm 0.1$ & $167 \pm 15$ & $46 \pm 7$ & $964 \pm 355$ & $16.0 \pm 1.9$ & $0.6 \pm 0.0$ \\
\hline & G2 (R) Recovery & 5 & $6.9 \pm 0.3$ & $0.7 \pm 0.1$ & $|32 \pm 2|$ & $38 \pm 7$ & $519 \pm 171$ & $15.8 \pm 1.7$ & $0.6 \pm 0.0$ \\
\hline & G5 (R) Recovery & 5 & $6.7 \pm 0.4$ & $0.7 \pm 0.1$ & $|2| \pm 14^{a}$ & $42 \pm 6$ & $388 \pm 123^{a}$ & $16.9 \pm 2.0$ & $0.6 \pm 0.0$ \\
\hline \multirow[t]{8}{*}{ Female } & GI (0) & 10 & $6.5 \pm 0.3$ & $0.8 \pm 0.1$ & $155 \pm 33$ & $42 \pm 7$ & $473 \pm 248$ & $14.4 \pm 2.4$ & $0.6 \pm 0.0$ \\
\hline & G2 $(0)$ & 10 & $6.6 \pm 0.4$ & $0.8 \pm 0.1$ & $153 \pm 28$ & $40 \pm 8$ & $470 \pm 245$ & $14.0 \pm 1.0$ & $0.5 \pm 0.0$ \\
\hline & G3 (250) & 10 & $6.6 \pm 0.4$ & $0.9 \pm 0.1$ & $153 \pm 29$ & $42 \pm 13$ & $643 \pm 369$ & $15.2 \pm 1.6$ & $0.5 \pm 0.1$ \\
\hline & G4 (500) & 10 & $6.7 \pm 0.7$ & $0.8 \pm 0.1$ & $158 \pm 62$ & $50 \pm 36$ & $538 \pm 245$ & $13.9 \pm 1.4$ & $0.5 \pm 0.0$ \\
\hline & G5 $(1,000)$ & 10 & $6.6 \pm 0.4$ & $0.8 \pm 0.1$ & $174 \pm 53$ & $46 \pm 23$ & $647 \pm 291$ & $15.8 \pm 1.2$ & $0.5 \pm 0.1$ \\
\hline & GI (0) Recovery & 5 & $6.5 \pm 0.5$ & $0.8 \pm 0.1$ & $167 \pm 15$ & $46 \pm 7$ & $964 \pm 355$ & $16.0 \pm 1.9$ & $0.6 \pm 0.0$ \\
\hline & G2 (R) Recovery & 5 & $6.9 \pm 0.6$ & $0.8 \pm 0.0$ & $|32 \pm 2|$ & $38 \pm 7$ & $519 \pm 171$ & $15.8 \pm 1.7$ & $0.6 \pm 0.0$ \\
\hline & G5 (R) Recovery & 5 & $7.2 \pm 0.6$ & $0.9 \pm 0.0^{\mathrm{b}}$ & $121 \pm 14$ & $42 \pm 6$ & $388 \pm 123$ & $16.9 \pm 2.0$ & $0.6 \pm 0.0$ \\
\hline
\end{tabular}

Notes: Significant differences versus GI $\left({ }^{\mathrm{a} P}<0.0 \mathrm{I}\right)$ and $\mathrm{G} 2\left({ }^{\mathrm{b} P}<0.05\right)$. Figures are presented as mean \pm standard deviation.

Abbreviations: TP, total protein; A/G, albumin/globulin ratio; AST, aspartate aminotransferase; ALT, alanine aminotransferase; CK, creatine kinase; BUN, blood urea nitrogen; Crea, creatinine.

group. Atrophy of the right seminal vesicle was observed in male rats from the $500 \mathrm{mg} / \mathrm{kg}$ group. A red nodule in the stomach (two cases) and a light brown change in the right kidney color (one case) occurred in female rats from the control group. A reddish stomach nodule was found in two female rats from the $250 \mathrm{mg} / \mathrm{kg}$ group. A reddish nodule in the stomach, a reddish color change in the caudal lobe of the liver, a light brown color change in the right kidney, and fragility of the right adrenal gland were observed in female rats from the $500 \mathrm{mg} / \mathrm{kg}$ group. One red nodule and a yellow mass in the stomach, a light brown color change of the right kidney, and a reddish color change in the accessory lobe of the liver were documented in female rats from the $1,000 \mathrm{mg} / \mathrm{kg}$ group (see Table 4 ). Given that these changes were also observed in the control group and did not show dose-dependency, they were deemed not to be due to application of $\mathrm{ZnO}^{\mathrm{SM} 20(-)}$.

The weight of the epididymis decreased significantly $(P<0.05)$ in male rats from the $500 \mathrm{mg} / \mathrm{kg}$ group. The weight of the thymus also decreased significantly in male rats from the $1,000 \mathrm{mg} / \mathrm{kg}$ recovery group in comparison with the control group $(P<0.05)$. There was no significant difference in organ weight for female rats in comparison with the control group. Since the changes in organ weight occurred sporadically and independent of dosage, they were not considered to represent toxic effects of $\mathrm{ZnO}$.

Areas of necrosis with regenerative hyperplasia and pigmentation were found in the livers of female rats in the control and 1,000 mg/kg groups; this could be the result of pressure from the bandage and repeated application of the test materials, and not from the test material itself, given that it occurred in both these groups. Also, lesions in other organs were considered as nonspecific that can be frequently seen in other repeated toxicology testing.

\section{Analysis of tissue distribution}

After repeated application for 90 days, concentrations of $\mathrm{ZnO}$ NPs were determined in the plasma, feces, brain, liver, kidneys, ovaries, testes, spleen, lungs, stomach, small intestine, large intestine, and skin. No differences in ZnO NP concentration were seen between females and males, with higher concentrations found in the liver, large intestine, small intestine, and feces upon increasing doses when compared with the negative and vehicle control groups. However, $\mathrm{ZnO}$ NP concentrations remained the same in the brain, testes, ovaries, spleen, stomach, plasma, kidneys, and lung as in the negative and vehicle control groups. The increased concentrations in the liver, large intestine, small intestine, and feces could be explained by rats ingesting the test material via licking behavior. Washing was done with distilled water prior to necropsy, but the test material seemed to remain on the skin. It was difficult to determine absorption through the skin during this experiment.

\section{Discussion}

$\mathrm{ZnO}$ NPs may enter the body via a number of routes. The skin is a potentially important route because it is the largest organ in the body, accounting for more than $10 \%$ of body mass. Since ZnO NPs are frequently used as an ingredient 


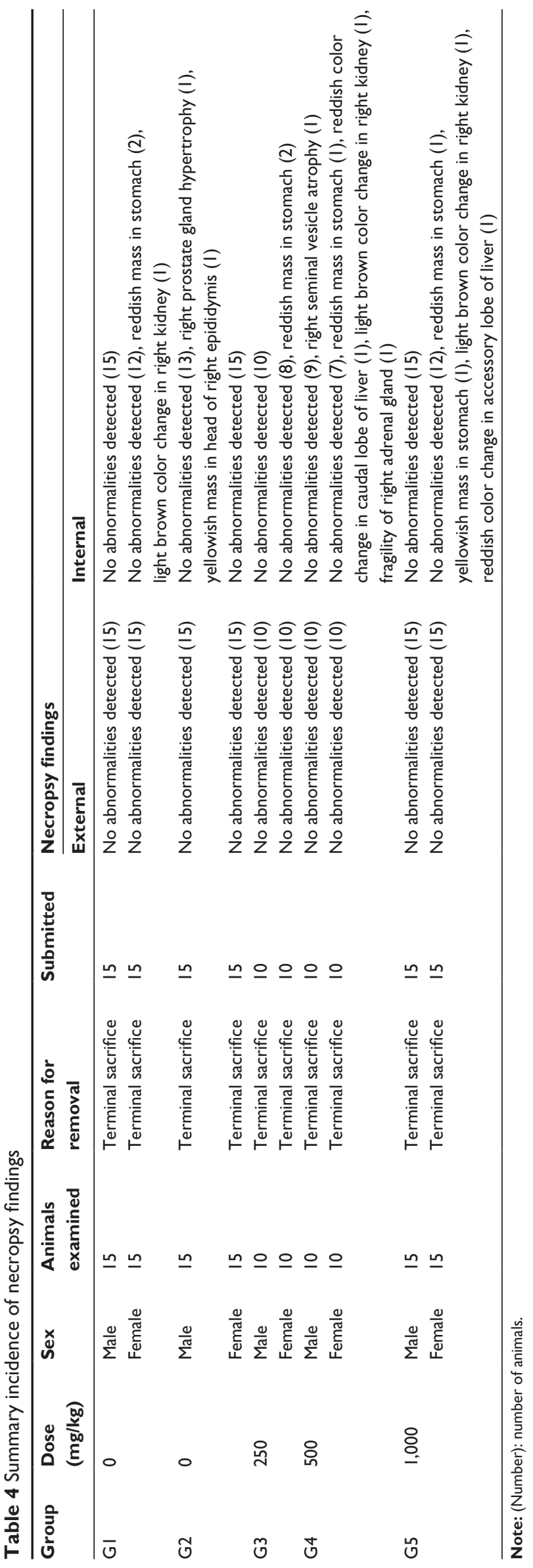

in sunscreens, safety concerns persist about these products. ${ }^{6}$ This study investigated the potential toxicity of $\mathrm{ZnO}$ NPs in internal organs and at the dermal administration site in Sprague Dawley rats after repeated exposure for 90 days. Since Kertesz et $\mathrm{al}^{5}$ demonstrated that penetration of nanomaterials into the skin after exposure may be time-dependent, it was important to evaluate the potential toxicity of $\mathrm{ZnO}$ NPs over a prolonged period of exposure. Although concern regarding the potential toxicity of ZnO NPs has been mounting, only a limited number of studies are available. ${ }^{7,8} \mathrm{~A}$ study by Pasupuleti et $\mathrm{al}^{9}$ reported lesions in the liver and pancreas after oral administration of ZnO NPs in rats. The same study also suggested that $\mathrm{ZnO} N P s$ were more toxic than $\mathrm{ZnO}$ microparticles, even at a lower dose. A 28-day repeated-dose toxicity study of dermally administered $\mathrm{ZnO} \mathrm{NPs}^{4}$ reported significant changes in the collagen content of the skin at the application site but no systemic toxicity, except for an increased clotting time. Severe damage to the liver and lung tissues was observed when ZnO NPs were inhaled. ${ }^{10}$ There is a broad consensus that the principal human health risk may be from inhalation of NPs. However, dermal contact may increase this risk. Some researchers have proposed that there would not be any toxicologic concerns with dermally applied $\mathrm{ZnO}$ NPs; $;{ }^{11,12}$ however, others have demonstrated absorption of $\mathrm{ZnO}$ particles through human skin or in a model equivalent to human skin. ${ }^{1,13}$ Hence, concerns about ZnO NPs are ongoing, not only with regard to possible skin toxicity, but also systemic toxicity. When $\mathrm{ZnO}$ NPs were administered through the oral or inhalational route, damage to the liver was evident. ${ }^{4,10}$ In the present study of the dermal toxicity of $\mathrm{ZnO}$ $\mathrm{NPs}$, although increased concentrations of $\mathrm{ZnO}$ were seen in the liver during the tissue distribution test, no important adverse effects were observed. Only temporary effects, such as local skin irritation, occurred in a dose-dependent manner. Adachi et $\mathrm{al}^{14}$ also recently reported development of spongiotic dermatitis at the site of application with increased doses of titanium dioxide NPs, which was caused by mechanical irritation and generation of reactive oxygen species by the uncoated titanium dioxide NPs on the skin surface.

Skin penetration studies showed that less than $0.03 \%$ of the zinc content in $\mathrm{ZnO}$ NPs penetrated the epidermis. ${ }^{11,12}$ No NPs were observed in the lower stratum corneum or viable epidermis. Even the penetration measurement using multiphoton tomography showed that $30 \mathrm{~nm} \mathrm{ZnO}$ NPs cannot penetrate skin. ${ }^{15}$ However, other studies have shown that small amounts of zinc from ZnO NPs in sunscreens could pass through the protective layers of skin when exposed to the sun in a real-life environment, and were detected in blood and urine. ${ }^{1}$ In a study of the repeated-dose dermal toxicity 
of $\mathrm{ZnO}$ NPs over 28 days, significant decreases in collagen content were found in $\mathrm{ZnO}$-treated groups, implying that $\mathrm{ZnO}$ NPs penetrate deeply into the dermis and damage the collagen layer. ${ }^{15}$ Additional concerns in that study were the penetration of NPs into diseased or sunburnt skin with decreased barrier function. Interestingly, even in ultraviolet B-damaged skin with defective barrier function, $\mathrm{ZnO}$ was observed to stay in the epidermis and be unable to penetrate viable skin. Finally, the formulation or coating used for ZnO NPs may affect their penetration in skin. Leite-Silva et $\mathrm{al}^{17}$ demonstrated that coated $\mathrm{ZnO}$ NPs dispersed in a water-in-oil emulsion penetrated into skin more easily. In the present study, we did not find any evidence of skin penetration by $\mathrm{ZnO}$ NPs, and the increased concentrations found in the liver, small intestines, large intestines, and feces could be interpreted as oral ingestion of the test material by licking behavior. Systemic absorption of $\mathrm{ZnO}$ NPs via skin absorption seemed to be very limited. Even when applied to the dermis chronically, penetration of $\mathrm{ZnO}$ NPs may not be increased. To our knowledge, this is the first subchronic toxicity study of dermally applied ZnO NPs.

\section{Conclusion}

This study evaluated changes in internal organs, various bodily parameters, and skin after applying ZnO NPs dermally for 90 days. We evaluated the toxicity of these NPs in target organs, but there was no study-related internal organ toxicity except for temporary, dose-dependent inflammation of the skin at the application site. Therefore, there was no observed adverse effects of $\mathrm{ZnO}$ (20 nm, negative charge) up to $1,000 \mathrm{mg} / \mathrm{kg}$ body weight in both sexes of rats.

\section{Acknowledgment}

This research was supported by a grant (10182MFDS991) from the Ministry of Food and Drug Safety between 2010 and 2013, and Basic Science Research Program through the National Research Foundation of Korea (NRF), funded by the Ministry of Science, ICT and Future Planning (NRF2013R1A2A2A01068137).

\section{Disclosure}

The authors report no conflicts of interest in this work.

\section{References}

1. Gulson B, McCall M, Korsch M, et al. Small amounts of zinc from zinc oxide particles in sunscreens applied outdoors are absorbed through human skin. Toxicol Sci. 2010;118(1):140-149.

2. Smijs TG, Bouwstra JA. Focus on skin as a possible port of entry for solid nanoparticles and the toxicological impact. J Biomed Nanotechnol. 2010;6(5):469-484.

3. Martorano LM, Stork CJ, Li YV. UV irradiation-induced zinc dissociation from commercial zinc oxide sunscreen and its action in human epidermal keratinocytes. J Cosmet Dermatol. 2010;9(4):276-286.

4. Surekha P, Kishore AS, Srinivas A, et al. Repeated dose dermal toxicity study of nano zinc oxide with Sprague-Dawley rats. Cutan Ocul Toxicol. 2012;31(1):26-32.

5. Kertesz Z, Szikszai Z, Gontier E, et al. Nuclear microprobe study of $\mathrm{TiO}_{2}$-penetration in the epidermis of human skin xenografts. $\mathrm{Nucl}$ Instrum Methods Phys Res. 2005;231(1):280-285.

6. Burnett ME, Wang SQ. Current sunscreen controversies: a critical review. Photodermatol Photoimmunol Photomed. 2011;27(2):58-67.

7. Jang YS, Lee EY, Park YH, et al. The potential for skin irritation, phototoxicity, and sensitization of $\mathrm{ZnO}$ nanoparticles. Mol Cell Toxicol. 2012;8(2):171-177.

8. Lee SH, Pie JE, Kim YR, Lee HR, Son SW, Kim MK. Effects of zinc oxide nanoparticles on gene expression profile in human keratinocytes. Mol Cell Toxicol. 2012;8(2):113-118.

9. Pasupuleti S, Alapati S, Ganapathy S, Anumolu G, Pully NR, Prakhya BM. Toxicity of zinc oxide nanoparticles through oral route. Toxicol Ind Health. 2012;28(8):675-686.

10. Wang L, Ding W, Zhang F. Acute toxicity of ferric oxide and zinc oxide nanoparticles in rats. J Nanosci Nanotechnol. 2010;10(12):8617-8624.

11. Pirot F, Millet J, Kalia YN, Humbert P. In vitro study of percutaneous absorption, cutaneous bioavailability and bioequivalence of zinc and copper from five topical formulations. Skin Pharmacol. 1996;9(4):259-269.

12. Cross SE, Innes B, Roberts MS, Tsuzuki T, Robertson TA, McCormick P. Human skin penetration of sunscreen nanoparticles: in-vitro assessment of a novel micronized zinc oxide formulation. Skin Pharmacol Physiol. 2007;20(3):148-154.

13. Jeong SH, Kim JH, Yi SM, et al. Assessment of penetration of quantum dots through in vitro and in vivo human skin using the human skin equivalent model and the tape stripping method. Biochem Biophys Res Commun. 2010;394(3):612-615.

14. Adachi K, Yamada N, Yoshida Y, Yamamoto O. Subchronic exposure of titanium dioxide nanoparticles to hairless rat skin. Exp Dermatol. 2013;22(4):278-283.

15. Darvin ME, König K, Keller-Hoefer M, et al. Safety assessment by multiphoton fluorescence/second harmonic generation/Hyper-Rayleigh scattering tomography of $\mathrm{ZnO}$ nanoparticles used in cosmetic products. Skin Pharmacol Physiol. 2012;25(4):219-226.

16. Monteiro-Riviere NA, Wiench K, Landsiedel R, Schulte S, Inman AO, Riviere JE. Safety evaluation of sunscreen formulations containing titanium dioxide and zinc oxide nanoparticles in UVB sunburned skin: an in vitro and in vivo study. Toxicol Sci. 2011;123(1):264-280.

17. Leita-Silva VR, Lamer ML, Sanchez WY, et al. The effect of formualtion on the penetration of coated and uncoated zinc oxide nanoparticles into the viable epidermis of human skin in vivo. Eur J Pharm Biopharm. 2013;84(2):297-308.
International Journal of Nanomedicine

\section{Publish your work in this journal}

The International Journal of Nanomedicine is an international, peerreviewed journal focusing on the application of nanotechnology in diagnostics, therapeutics, and drug delivery systems throughout the biomedical field. This journal is indexed on PubMed Central, MedLine, CAS, SciSearch $\AA$, Current Contents $\AA /$ Clinical Medicine,

\section{Dovepress}

Journal Citation Reports/Science Edition, EMBase, Scopus and the Elsevier Bibliographic databases. The manuscript management system is completely online and includes a very quick and fair peer-review system, which is all easy to use. Visit http://www.dovepress.com/ testimonials.php to read real quotes from published authors. 